\title{
COMPARISON BETWEEN TEA TREE OIL AND CHLORHEXIDINE MOUTH RINSE IN TREATMENT OF GINGIVITIS INDUCED BY ORTHODONTIC TREATMENT: A RANDOMIZED CONTROL CLINICAL STUDY
}

\author{
Ghada Elmehy* and Tamer Elamer Abo-Shady**
}

\begin{abstract}
Aim: This study was designed to compare the effects of tea tree oil and chlorhexidine mouth rinse in the treatment of gingivitis induced by orthodontic treatment.

Materials and Methods: Sixty patients undergoing orthodontic treatment and suffering from gingivitis were included and divided randomly into three groups, group I (20 patients): Patients received scaling and oral hygiene instructions, group II (20 patients): Patients received scaling, oral hygiene instructions and chlorhexidine mouth rinse and group III (20 patients): Patients received scaling, oral hygiene instructions and tea tree oil mouth rinse.

Results: The results of this study revealed that all treatment modalities achieved a statistically significant reduction of the mean plaque index, gingival index and papillary bleeding index throughout the six months evaluation period as compared to the mean base-line values $(\mathrm{P}<0.001)$. This 6-month controlled clinical study demonstrated that the tea tree oil mouth rinse had comparable anti-gingivitis activity with chlorhexidine mouth rinse which is known to produce significantly higher levels of extrinsic stain.
\end{abstract}

Conclusion: Due to side effects associated with the chlorhexidine mouth rinse, it is suggested that tea tree oil mouth rinse can be used instead, as it proved to have a distinct role in the management of gingivitis induced by orthodontic treatment.

KEY WORDS: Chronic gingivitis, Orthodontic treatment, Chlorhexidine mouth rinse, Tea tree oil mouth rinse.

\section{INTRODUCTION}

Orthodontic treatment with fixed appliances modifies the oral environment ${ }^{(1)}$. Plaque increases around bands and brackets ${ }^{(2)}$, the composition of the oral flora changes ${ }^{(3)}$, and cleaning becomes more difficult for the patient ${ }^{(4)}$. As a result, gingival inflammation and enamel decalcification around fixed appliances can result in the absence of preventive programs ${ }^{(5)}$.

* Ass. Professor of Orthodontics Department, Faculty of Dentistry, Tanta University.

** Lecture of Oral Medicine and Periodontology Department, Faculty of Dentistry, Tanta University 
Plaque control and prevention of gingivitis is the main goal for the prevention of periodontal diseases. Therefore, in addition to mechanical oral hygiene, the use of antiseptics is strongly recommended and performed ${ }^{(6)}$. Among a variety of antiseptic agents, chlorhexidine digluconate $(\mathrm{CHX})$ has been used and tested for many years. The efficiency of CHX $0.2 \%$ in preventing plaque formation and development of gingivitis has been demonstrated in previous publications ${ }^{(7,8)}$. To date, it represents the gold standard among the anti-plaque agents ${ }^{(9)}$.

Natural products have served as a major source of drugs for centuries, and about half of the pharmaceuticals in use today are derived from natural products ${ }^{(10)}$. Among these materials, tea tree oil (Melaleuca alternifolia) (TTO) is derived from the bark of tea tree ${ }^{(11)}$ and has a broad-spectrum antimicrobial activity ${ }^{(12)}$, anti-fungal ${ }^{(13)}$, anti-viral ${ }^{(14)}$, antioxidant (15) and anti-inflammatory effects ${ }^{(16,17)}$.

The aim of this study was to compare $0.2 \%$ CHX and $1 \%$ TTO mouthrinse plus scaling versus scaling alone on chronic gingivitis induced by orthodontic treatment.

\section{MATERIALS AND METHODS:}

A prospective randomized trial was carried out on 60 patients undergoing orthodontic treatment at the Department of Orthodontic, Faculty of Dentistry, Tanta University from April 2016 to January 2017. This study included 21 males and 39 females, the patients' ages ranged between 12 and 30 years. All of the patients were treated with fixed orthodontic appliances in the upper and lower arches and suffered from chronic gingivitis. Their informed consent was taken and all procedures were explained before treatment.

\section{Inclusion criteria:}

1. No clinical attachment loss (CAL).

2. Patients with good systemic health
3. Patients who are able to maintain good oral hygiene.

4. Patients with straight wire orthodontic appliances.

\section{Exclusion criteria:}

- Any systemic disease that could affect the periodontium.

- Pregnancy.

- Taking anti-inflammatory drugs, antibiotics or vitamins within the previous 3 month.

- Using mouth washes regularly

- Heavy smoking (> 10 cigarettes/day)

- History of alcohol abuse

- Participation in other clinical trials.

- History of previous orthodontic treatment.

\section{Materials}

- Australian tea tree oil (Melaleuca alternifolia) was used as a mouth rinse and was prepared follows:

Tea tree oil was purchased from Sigma ${ }^{\circledR}$ (Steinheim Germany). $1 \mathrm{ml}$ tea tree oil was diluted with $100 \mathrm{ml}$ warm water, resulting in a final concentration of $1 \%$ TTO ${ }^{(18)}$. From this solution, $15 \mathrm{ml}$ was used as a mouth rinse.

- Chlorhexidine $0.2 \%$ mouth rinse.

\section{Patients' groups}

Patients were divided randomly by random number table drawn up by a professor of statistics into three groups:

\section{Group I (Control group- 20 patients)}

All patients received oral hygiene instructions and scaling (with hand instruments) for all teeth + removal of all stains and polishing the teeth with a slow running bristle brush. 


\section{Group II (Test group- 20 patients)}

All patients received oral hygiene instructions and scaling (with hand instruments) for all teeth + removal of all stains and polishing the teeth with a slow running bristle brush $+0.2 \%$ chlorhexidine mouthrinse twice daily for 2 min with $15 \mathrm{ml}$.

\section{Group III (Test group- 20 patients)}

All patients were received oral hygiene instructions and scaling (with hand instruments) of all teeth + removal of all stains and polishing the teeth with a slow running bristle brush $+1 \%$ tea tree oil mouthrinse twice daily for $2 \mathrm{~min}$ with $15 \mathrm{ml}$.

No anti-inflammatory agents were prescribed after treatment.

\section{Clinical Measurements}

Plaque index (PI) according to Silness \& Loe, (1964) ${ }^{(19)}$, Gingival index (GI) according to Loe \& Silness, (1963) ${ }^{(20)}$, Papillary bleeding index (PBI) according to Mühlemann (1977) (21), intensity stain index (ISI) according to Loebene et al., (1989) $^{(22)}$ were evaluated on the labial surfaces of the 12 anterior teeth at 1,3 , and 6 months after treatment.

\section{Statistical analysis}

All the results were tabulated and statistically analyzed using computer software named the Statistical Package for Social Science (SPSS version 10). Comparison within and between the studied groups were performed with independent samples student t-test, paired t-test and one-way ANOVA (F-testing), at a level of $5 \%$ significance.

\section{RESULTS}

All patients participated in the whole study period. However, group III complained from intensive and unpleasant taste of the TTO solution.

In the meantime, the mean baseline values of plaque index (PI), gingival index (GI), Papillary bleeding index (PBI) and intensity stain index (ISI) showed no significant difference between the treated groups.

In the present study all treatment modalities achieved a statistically significant reduction of the mean PI \& GI and PBI scores which continued up to the end of the 6 months evaluation period as compared to the mean baseline values $(\mathrm{P}<0.001)$.

However, group II showed a more significant reduction in PI after 1, 3 and 6 months after treatment (Figure 1). Moreover, at all evaluation points the reduction in GI and PBI scores was statistically different and more obvious following the adjunctive therapy of the tested groups compared with the control group $(P<0.01 \& \mathrm{P}<0.001$; Table 1, Figures 2, 3 ).

Furthermore, the data showed that in group II, there was statistically significant increase in ISI as compared to group I \& group II and which continued up to the end of the 6 months evaluation period $(P<0.001$; Table 1, Figure 4). 
TABLE (1) Mean values of plaque index (PI), gingival index (GI), Papillary bleeding index (PBI) and intensity stain index (ISI) among the study groups at 1, 3 and 6 months post-treatment.

\begin{tabular}{|c|c|c|c|c|c|}
\hline & & $\begin{array}{c}\text { Group } \mathrm{I}=\text { scaling } \\
\text { only } \\
\mathbf{n}=\mathbf{2 0}\end{array}$ & $\begin{array}{c}\text { Group } \mathrm{II}=\text { scaling } \\
+\mathrm{CHX} \\
\mathrm{n}=\mathbf{2 0}\end{array}$ & $\begin{array}{c}\text { Group III= } \\
\text { scaling + TTO } \\
n=20\end{array}$ & $\begin{array}{c}\text { F-test } \\
\text { P }\end{array}$ \\
\hline \multirow{5}{*}{ PI } & $\begin{array}{c}\text { Base-line } \\
\text { (1) }\end{array}$ & $1.56 \pm 0.36$ & $1.67 \pm 0.25$ & $1.73 \pm 0.22$ & $\begin{array}{c}1.915 \\
\mathrm{P}=0.157\end{array}$ \\
\hline & 1 months(2) & $0.51 \pm 0.32$ & $0.25 \pm 0.19$ & $0.37 \pm 0.17$ & $\begin{array}{c}5.829 \\
\mathrm{P}<0.01\end{array}$ \\
\hline & $\begin{array}{c}3 \text { months } \\
\text { (3) }\end{array}$ & $0.57 \pm 0.34$ & $0.28 \pm 0.18$ & $0.45 \pm 0.26$ & $\begin{array}{c}5.578 \\
\mathrm{P}<0.01\end{array}$ \\
\hline & $\begin{array}{c}6 \text { months } \\
\text { (4) }\end{array}$ & $0.58 \pm 0.31$ & $0.28 \pm 0.21$ & $0.43 \pm 0.22$ & $\begin{array}{c}6.744 \\
P<0.01\end{array}$ \\
\hline & t- test & $\begin{array}{l}1 \text { vs } 2 \mathrm{P}<0.001 \\
1 \text { vs } 3 \mathrm{P}<0.001 \\
1 \text { vs } 4 \mathrm{P}<0.001\end{array}$ & $\begin{array}{l}1 \text { vs } 2 \mathrm{P}<0.001 \\
1 \text { vs } 3 \mathrm{P}<0.001 \\
1 \text { vs } 4 \mathrm{P}<0.001\end{array}$ & $\begin{array}{l}1 \text { vs } 2 \mathrm{P}<0.001 \\
1 \text { vs } 3 \mathrm{P}<0.001 \\
1 \text { vs } 4 \mathrm{P}<0.001\end{array}$ & \\
\hline \multirow{5}{*}{ GI } & $\begin{array}{c}\text { Base-line } \\
\text { (1) }\end{array}$ & $2.17 \pm 0.48$ & $2.25 \pm 0.48$ & $2.36 \pm 0.37$ & $\begin{array}{c}0.859 \\
\mathrm{P}=0.429\end{array}$ \\
\hline & $\begin{array}{c}1 \text { months } \\
\text { (2) }\end{array}$ & $0.65 \pm 0.23$ & $0.37 \pm 0.12$ & $0.33 \pm 0.14$ & $\begin{array}{c}18.732 \\
\mathrm{P}<0.001\end{array}$ \\
\hline & $\begin{array}{c}3 \text { months } \\
\text { (3) }\end{array}$ & $0.70 \pm 0.20$ & $0.31 \pm 0 . .11$ & $0.32 \pm 0.11$ & $\begin{array}{c}41.818 \\
\mathrm{P}<0.001\end{array}$ \\
\hline & $\begin{array}{c}6 \text { months } \\
\text { (4) }\end{array}$ & $0.72 \pm 0.19$ & $0.30 \pm 0.10$ & $0.30 \pm 0.13$ & $\begin{array}{c}54.366 \\
\mathrm{P}<0.001\end{array}$ \\
\hline & t- test & $\begin{array}{l}1 \text { vs } 2 \quad \mathrm{P}<0.001 \\
1 \text { vs } 3 \quad \mathrm{P}<0.001 \\
1 \text { vs } 4 \quad \mathrm{P}<0.001 \\
\end{array}$ & $\begin{array}{l}1 \text { vs } 2 \quad \mathrm{P}<0.001 \\
1 \text { vs } 3 \quad \mathrm{P}<0.001 \\
1 \text { vs } 4 \quad \mathrm{P}<0.001 \\
\end{array}$ & $\begin{array}{ll}1 \text { vs } 2 & \mathrm{P}<0.001 \\
1 \text { vs } 3 & \mathrm{P}<0.001 \\
1 \text { vs } 4 & \mathrm{P}<0.001\end{array}$ & \\
\hline \multirow{5}{*}{ PBI } & $\begin{array}{c}\text { Base-line } \\
\text { (1) }\end{array}$ & $2.53 \pm 0.67$ & $2.72 \pm 0.71$ & $2.91 \pm 0.71$ & $\begin{array}{c}1.435 \\
\mathrm{P}<0.001\end{array}$ \\
\hline & $\begin{array}{c}1 \text { months } \\
\text { (2) }\end{array}$ & $0.48 \pm 0.16$ & $0.13 \pm 0.11$ & $0.15 \pm 0.12$ & $\begin{array}{c}41.565 \\
\mathrm{P}<0.001 \\
\end{array}$ \\
\hline & $\begin{array}{c}3 \text { months } \\
\text { (3) }\end{array}$ & $0.51 \pm 0.16$ & $0.12 \pm 0.10$ & $0.14 \pm 0.12$ & $\begin{array}{c}56.039 \\
\mathrm{P}<0.001\end{array}$ \\
\hline & $\begin{array}{c}6 \text { months } \\
\text { (4) }\end{array}$ & $0.55 \pm 0.21$ & $0.13 \pm 0.10$ & $0.16 \pm 0.11$ & $\begin{array}{c}45.676 \\
\mathrm{P}<0.001\end{array}$ \\
\hline & $\mathrm{t}$ - test & $\begin{array}{l}1 \text { vs } 2 \quad \mathrm{P}<0.001 \\
1 \text { vs } 3 \quad \mathrm{P}<0.001 \\
1 \text { vs } 4 \quad \mathrm{P}<0.001\end{array}$ & $\begin{array}{ll}1 \text { vs } 2 & \mathrm{P}<0.001 \\
1 \text { vs } 3 & \mathrm{P}<0.001 \\
1 \text { vs } 4 & \mathrm{P}<0.001 \\
\end{array}$ & $\begin{array}{ll}1 \text { vs } 2 & \mathrm{P}<0.001 \\
1 \text { vs } 3 & \mathrm{P}<0.001 \\
1 \text { vs } 4 & \mathrm{P}<0.001\end{array}$ & \\
\hline \multirow{4}{*}{ ISI } & $\begin{array}{c}\text { Base-line } \\
\text { (1) }\end{array}$ & $00 \pm 00$ & $00 \pm 00$ & $00 \pm 00$ & \\
\hline & $\begin{array}{c}1 \text { months } \\
\text { (2) }\end{array}$ & $0.17 \pm 0.15$ & $1.47 \pm 0.47$ & $0.13 \pm 0.23$ & $\begin{array}{l}114.667 \\
\mathrm{P}<0.001\end{array}$ \\
\hline & $\begin{array}{c}3 \text { months } \\
\text { (3) }\end{array}$ & $0.19 \pm 0.16$ & $1.82 \pm 0.74$ & $0.14 \pm 0.23$ & $\begin{array}{c}85.478 \\
\mathrm{P}<0.001\end{array}$ \\
\hline & $\begin{array}{c}6 \text { months } \\
\text { (4) }\end{array}$ & $0.22 \pm 0.18$ & $2.00 \pm 0.64$ & $0.15 \pm 0.24$ & $\begin{array}{l}127.982 \\
\mathrm{P}<0.001\end{array}$ \\
\hline
\end{tabular}




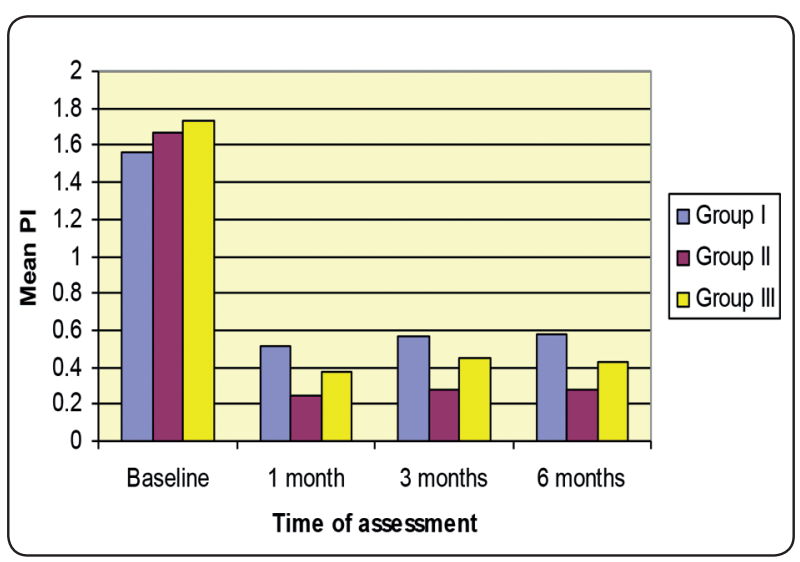

Fig. (1) Mean values of plaque index (PI) among the study groups at base-line, 1,3 and 6 months post-treatment.

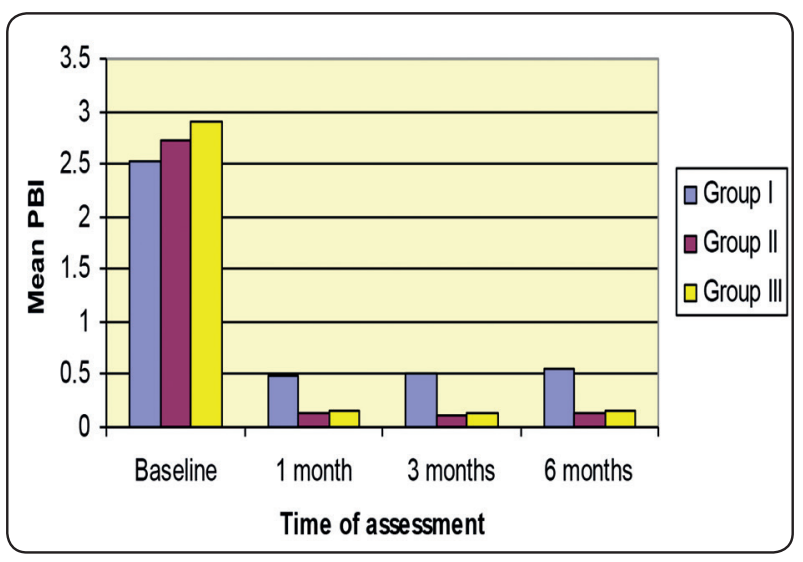

Fig. (3) Mean values of papillary bleeding index (PBI) among the study groups at base-line, 1,3 and 6 months posttreatment.

\section{DISCUSSION}

CHX is a relatively safe drug; this may be due to its poor systemic absorption. However, it shows some side effects such as objectionable taste, discoloration of teeth and restorations, as well as brownish discoloration of the dorsum of the tongue ${ }^{(23)}$. Scientific evidence suggests that tea tree oil may be useful in the maintenance of oral hygiene, prevention of dental disease and may be an effective agent for both the prevention and treatment of oral infections ${ }^{(18)}$. The present study was carried out to compare the $0.2 \% \mathrm{CHX}$ and $1 \%$ TTO mouth rinse plus scaling versus scaling alone on chronic gingivitis induced by orthodontic treatment.

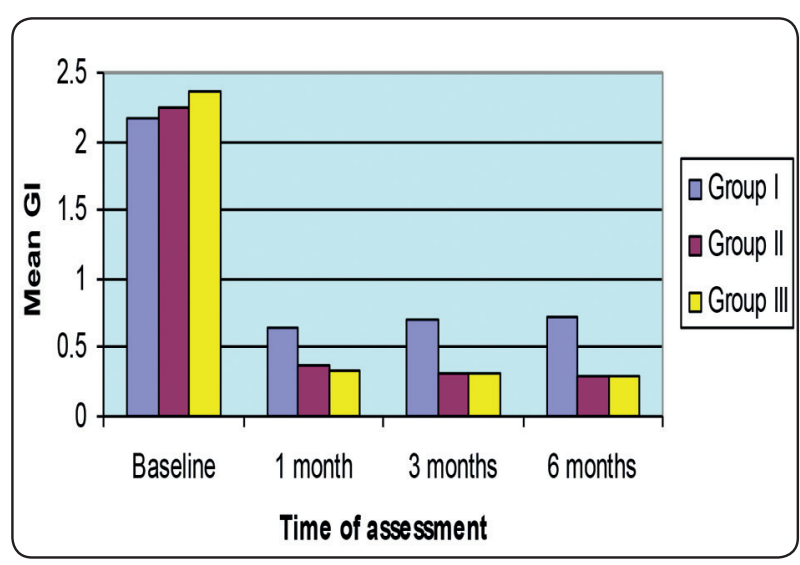

Fig. (2) Mean values of gingival index (GI) among the study groups at base-line, 1,3 and 6 months post-treatment.

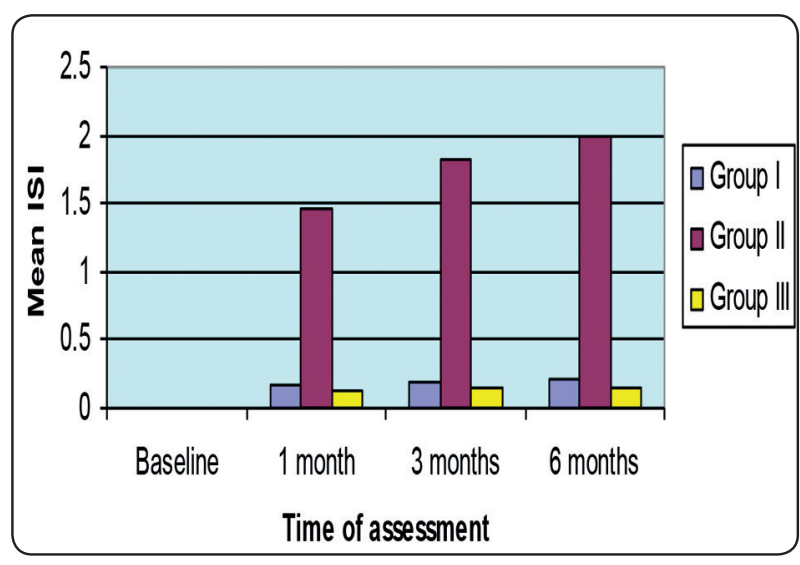

Fig. (4) Mean values of intensity stain index(ISI) among the study groups at base-line, 1,3 and 6 months posttreatment.

Results of PI revealed that there was a significant reduction at all evaluation periods in the three treated group. This clinical trial demonstrated that there was significant reduction in the PI in group II as compared to groups I and III at 1,3 and 6 months.

In CHX group, the reduction in PI may be attributed to the antiplaque effect of $\mathrm{CHX}$. It is postulated that $\mathrm{CHX}$ achieved its antiplaque effect as a result of an immediate bactericidal action at the time of application, followed by a prolonged bacteriostatic action as a result of $\mathrm{CHX}$ adsorbing to the pellicle coated enamel surface. This implied that tooth surface bound CHX is of great importance in preventing plaque formation ${ }^{(24)}$. 
At all evaluation periods, the reduction in PI in TTO and control groups may be attributed to mechanical oral hygiene procedures. There was no statistically significant difference between group I and III in the mean PI during the study periods. The results of the present study were in agreement with the clinical results reported by Arweiler et al., (2000) ${ }^{(25)}$ who described the efficacy of a TTO used as mouthwash on plaque formation. They found that the plaque index in the group treated by TTO mouth wash did not differ from placebo mouthwash on any day from the study period. Also, our results were in agreement with the clinical results reported by Soukoulis \& Hirsch, (2004) (11) who performed a double-blind, longitudinal study to evaluate the effect of TTO gel $(2.5 \%)$ applied to toothbrush twice daily. They found that TTO did not reduce plaque scores.

Results of the present study showed a significant reduction in the GI and PBI scores during the study periods in all groups as compared to baseline values. In groups II and III, results showed a significant improvement in GI and PBI as compared to group I at all evaluation periods. These results were in agreement with Charles et al., (2004) (26), Olympio et al., (2006) ${ }^{(4)}$ and Lorenz et al., (2006) ${ }^{(27)}$ who reported that CHX was able to inhibit plaque regrowth and gingivitis. The reduction in GI and PBI in CHX group may be attributed to antibacterial action of CHX. At low concentration, the $\mathrm{CHX}$ is bacteriostatic, whereas at higher concentration the CHX is rapidly bactericidal ${ }^{(28)}$.

These results are consistent with the study of Soukoulis et al., (2004) ${ }^{(29)}$ in which TTO gel used twice daily with a toothbrush as a dentifrice was found to significantly reduce inflammation and bleeding of the gingiva in people with severe gingivitis. Also, the previous results were in agreement with Juergens et al., (1998) (30), Hart et al., (2000) (31) and Brand et al., (2001) (16), who found decreased gingival inflammation with the use of TTO and explained their results by the anti-inflammatory activity of TTO. Brand et al., (2001) (16) showed that TTO suppressed the production of superoxide by human monocytes. Another extra explanation of the anti-inflammatory of TTO was explained by Juergens et al., (1998) ${ }^{(30)}$ who showed a significant decrease in the production of cytokines (TNF- $\alpha$ \& IL-1 $\beta$ ) from lipopolysaccharides (LPS) stimulated monocytes in response to the administration of Soledum ${ }^{\circledR}$ (containing 1, 8-cineole).

The present results revealed that levels of extrinsic tooth stain were significantly higher in the chlorhexidine group than in the TTO and control groups, this result was similar to that reported by Charles et al., (2004) (26), who compared between essential oil mouthrinse and the chlorhexidine mouthrinse and they found that chlorhexidine mouthrinse group had significantly more calculus and extrinsic tooth stain than either the essential oil mouthrinse group or the control group. Olympio et al., (2006) (4) analyzed the results of using chlorhexidine dentifrices in relation to dental plaque, gingivitis, bleeding, calculus and enamel extrinsic staining development in orthodontic patients. They found that chlorhexidine dentifrices significantly increased the mean of the stain index, although most of the patients did not notice the stains. Also, our results were in agreement with Overholser et al., (1990) ${ }^{(32)}$ and Lorenz et al., (2006) (27) who found that the chlorhexidine significantly increased the mean of the stain index.

Therefore, it is likely that the chlorhexidine mouthrinse could have a greater role in situations when short-term plaque control is critical and usual mechanical oral hygiene procedures are difficult, e.g., in the immediate post-operative period after periodontal surgery, and the TTO mouthrinse could have a role in the longer-term control of plaque and gingivitis during the maintenance phase of therapy and orthodontic treatment.

In summary, this 6-month controlled comparative clinical trial demonstrated that the TTO mouthrinse and the chlorhexidine mouthrinse had comparable anti-gingivitis activity, with the chlorhexidine mouthrinse producing significantly higher levels of extrinsic stain. 


\section{REFERENCE}

1. Derks A, Kuijpers-Jagtman AM, Frencken JE, Van't Hof MA, Katsaros C. Caries preventive measures used in orthodontic practices: an evidence-based decision? Am J Orthod Dentofacial Orthop. 2007; 132(2):165-170.

2. Pender N. Aspects of oral health in orthodontic patients. Britsh Journal of Orthodontics. 1986;13: 95-103.

3. Lundström F and Krasse B. Streptococcus mutans and lactobacilli frequency in orthodontic patients; the effect of chlorhexidine treatments. Eur J Orthod. 1987;9(2):109116 .

4. Olympio KP, Bardal PA, de M Bastos JR, Buzalaf MA. Effectiveness of a chlorhexidine dentifrice in orthodontic patients: a randomized-controlled trial. J Clin Periodontol. 2006;33(6):421-6.

5. Derks A, Katsaros C, Frencken JE, van’t Hof MA, Kuijpers-Jagtman AM. Caries-inhibiting effect of preventive measures during orthodontic treatment with fixed appliances. A systematic review. Caries Res. 2004;38(5): 413-20.

6. Baehni PC, Takeuchi Y. Anti-plaque agents in the prevention of biofilm-associated oral diseases. Oral Dis. 2003;9 Suppl 1:23-9.

7. Fardal O, Turnbull RS. A review of the literature on use of chlorhexidine in dentistry. J Am Dent Assoc. 1986;112(6):863-869

8. Addy M, Moran JM. Clinical indications for the use of chemical adjuncts to plaque control: chlorhexidine formulations. Periodontol 2000. 1997;15:52-54.

9. Jones CG. Chlorhexidine: is it still the gold standard? Periodontol 2000. 1997; 15:55-62.

10. Clark AM. Natural products as a resource for new drugs. Pharm Res. 1996;13: 1133-44.

11. Soukoulis S, Hirsch R. The effects of a tea tree oilcontaining gel on plaque and chronic gingivitis. Aust Dent J. 2004;49(2):78-83

12. Carson CF, Riley TV. Antimicrobial activity of the major components of the essential oil of Melaleuca alternifolia. J Appl Bacteriol. 1995;78(3):264-9.

13. Jandourek A, Vaishampayan JK, Vazquez JA. Efficacy of melaleuca oral solution for the treatment of fluconazole refractory oral candidiasis in AIDS patients. AIDS. 1998;12(9):1033-7.
14. Carson CF, Ashton L, Dry L, Smith DW, Riley TV. Melaleuca alternifolia (tea tree) oil gel $(6 \%)$ for the treatment of recurrent herpes labialis. J Antimicrob Chemother. 2001;48(3):450-451.

15. Kim HJ, Chen F, Wu C, Wang X, Chung HY, Jin Z. Evaluation of antioxidant activity of Australian tea tree (Melaleuca alternifolia) oil and its components. J Agric Food Chem. 2004;52(10):2849-54.

16. Brand C, Ferrante A, Prager RH, Riley TV, Carson CF, Finlay-Jones JJ, Hart PH. The water-soluble components of the essential oil of Melaleuca alternifolia (tea tree oil) suppress the production of superoxide by human monocytes, but not neutrophils, activated in vitro. Inflamm Res. 2001;50(4):213-9.

17. Koh KJ, Pearce AL, Marshman G, Finlay-Jones JJ, Hart PH. Tea tree oil reduces histamine-induced skin inflammation. Br J Dermatol. 2002;147(6):1212-7.

18. Groppo FC, Ramacciato JC, Simões RP, Flório FM, Sartoratto A. Antimicrobial activity of garlic, tea tree oil, and chlorhexidine against oral microorganisms. Int Dent J . 2002; 52(6):433-7

19. Sillness P and Loe J. Periodontal diseases (II): Correlation between oral hygiene and periodontal conditions. Acta Odonto Scand. 1964; 22: 121.

20. Loe JB and Silness P. Periodontal diseases in pregnancy (I): Prevalence and severity. Acta. Odonto. Scand. 1963; 21: 522 .

21. Mühlemann HR. Psychological and chemical mediators of gingival health]. Rev Odontostomatol (Paris). 1977;6(5):352-7. In Lobene RR, Mankodi SM, Ciancio SG, Lamm RA, Charles CH, Ross NM. Correlations among gingival indices: a methodology study. J Periodontol. 1989;60 (3):159-62.

22. Lobene RR, Mankodi SM, Ciancio SG, Lamm RA, Charles $\mathrm{CH} \&$ Ross NM. Correlations among gingival indices: A methodological study. Journal of Periodontology 1989;60: 159-162.

23. Hull PS. Chemical inhibition of plaque. J Clin Periodontol. 1980;7:431-442.

24. Jenkins S, Addy M, Wade W, et al. The mechanism of action of chlorhexidine. J Clin Periodontol 1988;15:415-424.

25. Arweiler NB, Donos N, Netuschil L, Reich E, Sculean A. Clinical and antibacterial effect of tea tree oil--a pilot study. Clin Oral Investig. 2000;4(2):70-3. 
26. Charles $\mathrm{CH}$, Mostler KM, Bartels LL, Mankodi SM. Comparative antiplaque and antigingivitis effectiveness of a chlorhexidine and an essential oil mouthrinse: 6-month clinical trial. J Clin Periodontol. 2004;31(10):878-84.

27. Lorenz K, Bruhn G, Heumann C, Netuschil L, Brecx M, Hoffmann T. Effect of two new chlorhexidine mouthrinses on the development of dental plaque, gingivitis, and discolouration. A randomized, investigator-blind, placebocontrolled, 3-week experimental gingivitis study. J Clin Periodontol. 2006;33(8):561-7.

28. Davies A.The mode of action of chlorhexidine. J Periodontal Res Suppl. 1973;12:68-75.

29. Soukoulis S, Hirsch R. The effects of a tea tree oil-containing gel on plaque and chronic gingivitis. Australian Dental Journal 2004;49:(2):78-83.
30. Juergens UR, Stöber M, Vetter H. Inhibition of cytokine production and arachidonic acid metabolism by eucalyptol (1.8-cineole) in human blood monocytes in vitro. Eur $\mathbf{J}$ Med Res. 1998; 3(11):508-10.

31. Hart PH, Brand C, Carson CF, Riley TV, Prager RH, Finlay-Jones JJ. Terpinen-4-ol, the main component of the essential oil of Melaleuca alternifolia (tea tree oil), suppresses inflammatory mediator production by activated human monocytes. Inflamm Res. 2000;49(11):619-26.

32. Overholser CD, Meiller TF, DePaola LG, Minah GE, Niehaus C. Comparative effects of 2 chemotherapeutic mouthrinses on the development of supragingival dental plaque and gingivitis. J Clin Periodontol. 1990 Sep; 17(8):575-9. 